\title{
Effects of Cyber Bullying on Teenagers: a Short Review of Literature
}

\author{
Mir Ali Raza Talpur¹, Tabinda Touseef ${ }^{2}$, Syed Daniyal Ahmed Jilanee ${ }^{1}$, Muhammad Mubashir Shabu ${ }^{3}$ and \\ Ali Khan ${ }^{4 *}$ \\ ${ }^{1}$ Liaquat National Medical College and Hospital, Pakistan \\ ${ }^{2}$ Jinnah Medical and Dental College, Pakistan
}

${ }^{3}$ Karachi Medical and Dental College, Pakistan

${ }^{4}$ Dow University of Health and Sciences, Pakistan

*Corresponding author: Ali Khan, 4Dow University of Health and Sciences, Karachi, Pakistan.

Received Date: November 07, 2018

Published Date: November 26, 2018

\begin{abstract}
Among the numerous advantages of the internet, there is an unintended outcome of the internet's extensive reach: the growing rate of harmful offences against children and teens. Cyber-bullying victimization has recently received a fair amount of attention due to some heart-breaking events orbiting in schools and even at homes. Although research has already demonstrated a number of serious consequences of cyber-victimization, many questions remain unanswered concerning the impact of cyber-bullying. This study gathers literature from 18 studies pieces together only the factors that kick-start cyber-bullying perpetration and victimization but also the effects of bullying on the victims as well as the bullies.
\end{abstract}

Keywords: Cyber-bully; Teenagers; Effects; Perpetrators; Victims

\section{Introduction}

Cyber-bullying interactions are usually defined as "repeated, harmful interactions which are deliberately offensive, humiliating, threatening, and power assertive, and are enacted using electronic equipment, such as cell (mobile) phones or the Internet, by one or more individuals towards another" [1]. It might be a continuation of real life bullying but can also exist on its own [2].

Smith et al divided cyber-bullying in seven sub-categories, namely: text message bullying, picture/ video clip bullying, phone call bullying, email bullying, chat-room bullying, bullying through instant messaging (18\%) and bullying via websites among which picture/video clip and phone call were perceived to have the most impact [3]. Even though chat room, instant messaging and email bullying were perceived to have the least impact on the victim another study deems it most common among all (18\% and $13.8 \%$, respectively) [4].

\section{Review of Literature}

\section{Literature search strategy}

A thorough search of medical literature was conducted on Pubmed, Google scholar and Scopus databases. The key MeSH and non-MeSH terms were "Cyber-bully", "teenagers", "Effects", "Perpetrators" and "Victims". Literature search was confined to English language literature only. Medical literature from the past two decades was included in this research. Studies reporting the outcomes of cyber-bullying in healthy teenagers (13-19 years of age) were included whereas studies reporting psychological outcome in relation to other pathologies, victims primarily being older than 19 years of age and outcomes in mentally disabled subjects were excluded from the study.

\section{Nature of harassment}

The nature of harassment ranges from ignoring, disrespecting, threatening, calling names, spreading rumors, email bombing, picking on and ridiculing [4] to hiding names while sending SMS or when in a chat room, kicking someone out of a chat room, and violating the privacy of someone by a webcam [5].

\section{Comparison with traditional bullying}

Electronic communications allows perpetrators to maintain anonymity, access to a wide audience and 24/7 attainability. In addition, private nature of the communication devoid of non-verbal 
quos makes cyber-bullying different from traditional bullying. Perpetrators may feel reduced responsibility and accountability leaving victims more vulnerable [6-8].

\section{Causes of cyberbullying perpetration}

According to studies there was no correlation between age and cyber-bullying ( $p=0.39$ ) [1]. Males were more likely to cyber-bully others than females $(p=0.021)$ [9]. Only $43.6 \%$ of cyber-bullies thought that their bullying behavior was harsh to very harsh on the victims (Cyber victims: 66.4\%), similarly, only 26\% thought their actions had an impact on their victim's life (Cyber victims: $34.6 \%$ ). Those who bullied others scored higher on the peer relationship problems scale $(p=0.001)$ [1]. Cyber-bully statuses were independently predicted by conduct $(\mathrm{OR}=2.6$; $95 \% \mathrm{CI}, 1.5-4.5$; $\mathrm{P}$ $<.001)$ and hyperactivity problems (OR $=2.4 ; 95 \% \mathrm{CI}, 1.4-3.9 ; \mathrm{P}<$ $.001)$ and pro-social problems (OR $=2.3 ; 95 \% \mathrm{CI}, 1.5-3.4 ; \mathrm{P}<.001)$. No significant difference was observed between children of two biological parents and children living in a family with other than two biological parents [4]. Traditional bullies tended to be cyberbullies as well $(\mathrm{p}<0.001)$. Within a group of school bullies, $85.5 \%$ reported that they were also victims and even though almost $30 \%$ in this group were cyber-bullies, $27.3 \%$ were cyberbully victims [10].

Anonymity associated with electronic communication tools promotes cyberbullying and makes it difficult to prevent $[7,10]$. The frequencies of public school students who indicated being cyberbullies were higher than those of the private school students [5].

Although the frequent use of communication tools significantly promoted cyber-bullying in female students $(p=0.001)$, male students did not have the same effect ( $p=0.431$ ). On the other hand, the role of risky internet use in promoting cyber-bullying was not significant for female students $(\mathrm{p}=0.721)$, it was significant for male students $(p=0.001)$ [11].

\section{Causes of cyberbullying victimization}

Age: Although a decrease is seen in exclusive school bullying from ages $14(16.6 \%)$ to 18 (7.1\%), cyber-bullying actually increases between the ages $14(6.2 \%)$ to $18(7.4 \%)$ [10].

Gender: Although some studies show no significant difference between the proportion of male and female adolescents who reported being bullied $(p=0.91)$ [9]. There are reports indicating higher occurrence of cyber-bullying among females than males $(18.3 \%$ vs $13.2 \%)[12,13]$.

Race/Ethnicity: Whites/Caucasians were more prone to be victimization [14].

Physical appearance: Females seen as less or more attractive than others were at the highest risk for harassment while some students were also targeted on the basis of disability [9].

Traditional bullying victim: Traditional bully victims were also likely to be cyber-victims $(p=0.022)[15]$.

Family composition: Cyber-victim only status was associated with living in a family with other than 2 biological parents $(6.2 \%$ vs $4 \%$ ) [4]. exual orientation: Youngsters who identified themselves as heterosexual were less likely to be victimized as compared to their non-heterosexual counterparts (6\% vs $10.5 \%$ ) [12].

School performance: Students who performed poorly in school (D \& F grade holders) were more than twice as likely to be victims of either traditional or online harassment, or both, as compared to students who received A-grades (16.1\% vs 7.4\%) [12].

Technology use: The risky internet use and usage frequency predicted cyber-bullying victimization significantly when compared with traditional victimization among female $(\Delta \mathrm{R} 2=.133, \mathrm{~F}(2,83)$ $=6.78, \mathrm{p}=.002)$ as well as male students $(\Delta \mathrm{R} 2=.216, \mathrm{~F}(2,108)$ $=15.98, \mathrm{p}=.000)$. (11) In another study, Eric Rice reported high levels of texting $(\mathrm{OR}=2.1 ; 95 \% \mathrm{CI}=1.1,4.0 ; \mathrm{P}<.05)$ and Internet use $(\mathrm{OR}=2.0 ; 95 \% \mathrm{CI}=1.0,3.64 ; \mathrm{P}<.05)$ were associated with being a cyber-victim [14].

Type of school: Public school students reported experiencing cyber harassment more frequently than those studying in the private school [5].

\section{Effects of cyberbullying on the perpetrator}

The association between cyberbully perpetrator and their mental health and well-being is equally important to take under consideration. Many studies reported that cyberbullyng does not only has negative effects on the its victims but also on the perpetrator as well It was observed that $39 \%$ of students who harassed others online dropped out of school and $37 \%$ showed delinquent behavior [1]. About $32 \%$ of online harassers were frequent substance abusers, while some reported frequent smoking and drunkenness. A study reported that about $16 \%$ perpetrators were severely depressed [1] while in another study there reports of bullies feeling unsafe in school [4]. This study also states a strong correlation between psychiatric, psychosocial and psychosomatic disorders with being a cyberbully or a cybervictim [4]. With the rise of cyberbullying there arise a hypothesis that students who cyberbully may feel greatly powerful by taking the advantage of immense anonymity and by targeting much bigger and wider audience [16]. It has also been speculated that the lack of immediate retaliation by the victim may provoke perpetrator towards harsher bullying [17]. A study ny Gini et al has shown that bullies are morally capable enough to judge actions but still have potential deficiencies with respect to moral sentiments and appear to have high levels of moral disengagement which is why they lack empathy for victim [18].

\section{Effects on cybervictims}

In relation to combating cyber-bullying males responded more actively and with physically retaliatory behavior, whereas females' responses indicated more passive and verbally retaliatory behavior [15]. About 1 in every 4 individuals reported fear for their safety most of whom most reported getting targeted by an adult. Sourander et al reported association between victimization and sleeping problems $(\mathrm{p}<0.001)$, bed-wetting, headaches $(\mathrm{p}<$ 0.001), recurrent abdominal pain and stomachaches. The same study states that victims experience numerous perceived problems, social anxiety, emotional disturbances and peer problems [4]. Hoff et al in their study found that students who were the targets of cyber bully reported several negative psychological effects. 
They experienced high levels of aggressiveness, powerlessness, sadness, and fear [15]. Girls who were victimized by cyberbully were significantly $(\mathrm{P}=0.003)$ more likely to reports 2-week sadness (36\% vs. $21 \%$ ), suicidal ideation (19\% vs. $12 \%)$, suicide plan $(15 \%$ vs. $11 \%)$, attempt ( $10 \%$ vs. $6 \%)$, and treatment for attempt $(3 \%$ vs. $2 \%$ ) as compared to victimized boys. This study also shows a strong association of suicidality in teens with victimization of bully, especially cyberbully [19].

Students categorized as "other" race (20\%) and Hispanics (14\%) presented with higher suicide ideation, as well as were more likely to report having made a suicide attempt $(10 \%$ and $11 \%$, respectively) compared to Caucasians (6\%) and African-Americans (8\%) [19]. The analysis showed that female cybervictims were more likely to inform adults than males $(p=0.012)$ and among students who knew someone being cyber bullied, only $30.1 \%$ told adults with no correlation to gender [9]. Non-heterosexual groups were far more likely to report bullying (33.1\% vs $14.5 \%)$ [12].

Both public and private school students revealed seeking help from their friends (28.6\% vs $43.6 \%$ ) however only a few of the public school students stated that they had asked for help from their teachers while none of the private school students reported asking help from them [5]. A study by ML Ybarra et al states that the victims of cyberbully undergoes variety of social problems which results in having them caught in detentions, suspensions and school avoiding behavior [20]. The same study shows that cyberbully victims experience paranoia due to which they tend to carry weapons with them [20]. The cyberbully victims are more likely to develop aggression against bullies and tend to become cyber bullies to take revenge and may experience the same negative impacts as being experienced by a perpetrator [20].

\section{Interventions}

Educating children: Warning from the dangers that lurk in cyber space and training of children must start at a young age, involving them in discussions about the dangers of bullying and how to by an ally when they see cyber-bullying behavior and who to report to? [15]

Educating teachers: Educators should become "safe contacts," giving students a place to turn if they are victims or want to report perpetrators [15].

Educating parents: Monitoring their child's online behavior, implementing internet usage rules and what to do if they discover that their child is a participant or a target is part of parent education in combating cyber-bullying [15]. The percentage of youth reporting the existence of parental rules on Web sites $(p<0.01)$, time allowed online ( $p<0.01)$, and filter restricting online activities $(\mathrm{p}<0.05)$ is higher among non-victims than among victims [13].

Role of school: Another role of schools is to help students cope with social tension especially those that center on relationship issues, assess of students in order to determine bullying behavior and get to the root of it [15].

Technological coping strategies: Instituting strict privacy settings on Internet-based technologies such as instant messengers and e-mails, changing usernames and or e-mail addresses [21].

\section{Conclusion}

Cyber-bullying is a multi-conceptual topic which requires immense research. After a thorough search of literature, we've concluded that cyber-bullying is one of the worst forms of bully which imparts its devastating effects on teenagers. Perpetrators of cyber-bully misuse the cyber resources in various ways to bully people online for the sake of their psychological satisfaction which badly influence the targeted victims as well as the active perpetrator.

A targeted victim, as a consequence of cyber-bully, may experience insecurities, poor school performance, addictions, psychosomatic disorders, retaliatory behavior, emotional distress, suicidal tendencies etc. This altogether adds to destruction of normal psychology of a teenager. Cyber-bullying also impacts the perpetrators with serious psychosomatic, psychiatric and psychosocial disorders. All the individuals involved in cyber-bully, either as a victim or a perpetrator, face some serious outcomes of this problem which can only be reduced by active measures to combat it.

\section{Acknowledgement}

None.

\section{Conflict of Interest}

Authors declare no conflict of interest.

\section{References}

1. Campbell MA, Slee PT, Spears B, Butler D, Kift S (2013) Do cyberbullies suffer too? Cyberbullies' perceptions of the harm they cause to others and to their own mental health. School Psychology International 34(6): 613-629.

2. Brandtzaeg PB, Staksrud E, Hagen I, Wold T (2009) Norwegian children's experiences of cyberbullying when using different technological platforms. Journal of Children and Media. 3(4): 349-365.

3. Smith PK, Mahdavi J, Carvalho M, Tippett N (2006) An investigation into cyberbullying, its forms, awareness and impact, and the relationship between age and gender in cyberbullying.

4. Sourander $\mathrm{A}$, Klomek $\mathrm{AB}$, Ikonen $\mathrm{M}$, Lindroos J, Luntamo $\mathrm{T}$, et al. (2010) Psychosocial risk factors associated with cyberbullying among adolescents: A population-based study. Arch Gen Psychiatry. 67(7): 720728

5. Topçu C, Erdur-Baker O, Capa-Aydin Y (2008) Examination of cyberbullying experiences among Turkish students from different school types. Cyberpsychol Behav 11(6): 643-648.

6. Huang Y-y, Chou C (2010) An analysis of multiple factors of cyberbullying among junior high school students in Taiwan. Computers in Human Behavior. 26(6): 1581-1590.

7. Dehue F, Bolman C, Völlink T (2008) Cyberbullying: Youngsters experiences and parental perception. Cyberpsychol Behav 11(2): 217223.

8. Heirman W, Walrave M (2008) Assessing concerns and issues about the mediation of technology in cyberbullying. Cyberpsychology: Journal of Psychosocial Research on Cyberspace 2(2).

9. Li Q (2006) Cyberbullying in schools: A research of gender differences. School Psychology International 27(2): 157-170.

10. Li Q (2007) New bottle but old wine: A research of cyberbullying in schools. Computers in Human Behavior 23(4): 1777-1791.

11. Erdur-Baker Ozgur (2010) Cyberbullying and its correlation to traditional bullying, gender and frequent and risky usage of internetmediated communication tools. New media \& society 12(1): 109-125. 
12. Schneider SK, O’Donnell L, Stueve A, Coulter RW (2012) Cyberbullying, school bullying, and psychological distress: A regional census of high school students. Am J Public Health 102(1): 171-177.

13. Mesch GS (2009) Parental mediation, online activities, and cyberbullying Cyberpsychol Behav 12(4): 387-393.

14. Rice E, Petering R, Rhoades H, Winetrobe H, Goldbach J, et al. (2015) Cyberbullying perpetration and victimization among middle-school students. Am J Public Health. 105(3): e66-e72.

15. Hoff DL, Mitchell SN (2009) Cyberbullying: Causes, effects, and remedies. Journal of Educational Administration. 47(5): 652-665.

16. Steffgen G, König A, Pfetsch J, Melzer A (2011) Are cyberbullies less empathic? Adolescents' cyberbullying behavior and empathic responsiveness. Cyberpsychol Behav Soc Netw 14(11): 643-648.
17. Conn K (2004) Bullying and harassment: A legal guide for educators: ASCD.

18. Gini G, Pozzoli T, Hauser M (2011) Bullies have enhanced moral competence to judge relative to victims, but lack moral compassion. Personality and Individual Differences 50(5): 603-608.

19. Messias E, Kindrick K, Castro J (2014) School bullying, cyberbullying, or both: correlates of teen suicidality in the 2011 CDC Youth Risk Behavior Survey. Compr Psychiatry 55(5): 1063-1068.

20. Ybarra ML, Diener-West M, Leaf PJ (2007) Examining the overlap in Internet harassment and school bullying: Implications for school intervention. J Adolesc Health 41(6 Suppl 1): S42-S50.

21. Tokunaga RS (2010) Following you home from school: A critical review and synthesis of research on cyberbullying victimization. Computers in Human Behavior 26(3): 277-287. 